\title{
Materials Architectures for Chemoresistive Gas-Sensing by Cross-Talk with Heterogeneous Catalysis. Principles, Synthesis and Applications
}

\author{
Mauro Epifani ${ }^{1}$ \\ ${ }^{1}$ Consiglio Nazionale delle Ricerche - Istituto per la Microelettronica e Microsistemi, via Monteroni c/o \\ Campus Universitario, 73100 Lecce, Italy \\ mauro.epifani@le.imm.cnr.it
}

\begin{abstract}
:
A relationship may be established between chemoresistive gas sensors and heterogeneous catalysis. In catalysis, the focus is on the desired chemical transformations of a known gas-phase. In gassensors, the gas-phase is expected to be of unknown composition and in very low concentrations (ppm or even $\mathrm{ppb}$ ). It is necessary to amplify and translate into a readable signal the outcome of the chemical reactions at the sensor-gas interface. For this reason the focus is on the electrical behavior of the oxide sensing layer. It is then not surprising that the same concepts of catalysis can be useful in gas-sensors, provided the considered materials have semiconducting properties. For instance, an oxide nanocrystal surface-covered with a layer of another oxide, an architecture which is the nanosized counterpart of bulk catalytic systems, may provide enhanced gas response if the surface oxide has enhanced reaction with the gaseous analyte and may efficiently transport the generated charges. In this work, the synthesis of the related architectures suggested by the heterogeneous catalysis field will be reviewed, comprising $\mathrm{TiO}_{2}-\mathrm{V}_{2} \mathrm{O}_{5}, \mathrm{TiO}_{2}-\mathrm{WO}_{3}$ and $\mathrm{TiO}_{2}-\mathrm{MoO}_{3}$ systems. The complex characterization work necessary for unravel their complex composition and structure will be summarized. Finally, examples of gas-sensing properties will be shown, aimed to demonstrate that the starting principle was actually implemented, and that the results pave the way for the design and application of a whole class of materials architectures.
\end{abstract}

Key words: chemoresistive sensors, metal oxide nanocrystals, surface modification, heterojunctions, solvothermal synthesis.

\section{Topic and Results}

The modification of metal oxides by additives or dopants is well known for improving the performances of chemoresistive gas-sensors. A well-known mechanism of additive action is spill-over, which is an application of heterogeneous catalysis concept. Chemo resistive gas sensing has indeed close relationship with heterogeneous catalysis, hence it is reasonable to search for hints from such field about how to improve chemoresistive sensors. A well known catalyst system is the titania-supported vanadium pentoxide [2], a powerful promoter of oxidation reactions of many organic compounds [3], which makes it an ideal sensor candidate, at the condition that the surface vanadium oxides species could enhance the electronic exchange between the gaseous analyte and the titania support. Based on this set of consideration, the first step was the experimental accomplishment of the desired structure, where anatase nanocrystals bear vanadium (V) oxide species onto the surface. This aim was achieved by coupling sol-gel and solvothermal synthesis, as detailed in [1]. It is easy to conclude that it cannot be the only case of interest, due to the extensive catalysis literature on supported oxides. Indeed, the synthesis approach could be easily extended to other popular heterogeneous catalysts like $\mathrm{TiO}_{2}-\mathrm{WO}_{3}$ [2-3] and $\mathrm{TiO}_{2}-\mathrm{MoO}_{3}$ [4]. The next step was the materials characterization to ascertain the presence of the second oxide layer, its structure and composition. A large set of techniques was necessary, since there is no formation of any "shell" onto the small (about 4 $\mathrm{nm}) \mathrm{TiO}_{2}$ nanocrystals. The results univocally point to the presence of a few layers of the second oxide onto the titania core, with phase segregation only occurring when a threshold concentration is exceeded. It was then time to test the gas-sensing properties of the prepared systems in order to check the validity of the above mentioned working hypothesis. In the case of $\mathrm{TiO}_{2}-\mathrm{V}_{2} \mathrm{O}_{5}$, the calibration curves in Fig. 
1 show that the modified nanocrystals could largely outperform pure $\mathrm{TiO}_{2}$ at as low as 200 ${ }^{\circ} \mathrm{C}$ temperature, an operating condition much less demanding than for pure $\mathrm{TiO}_{2}$, which needs much higher temperatures for giving larger responses.

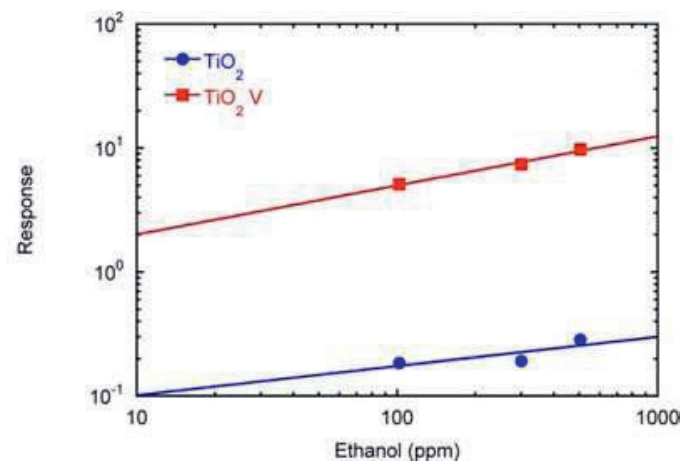

Fig. 1. Ethanol calibration curves for $\mathrm{TiO}_{2}$ and $\mathrm{TiO}_{2}-\mathrm{V}_{2} \mathrm{O}_{5}$ sensors as a function of ethanol square concentration pulses at an operating temperature of $200{ }^{\circ} \mathrm{C}$ and $40 \% \mathrm{RH}$. (Modified with permission from [1]).

Same observations can be drawn as concerns the $\mathrm{TiO}_{2}-\mathrm{WO}_{3}$ system [2] (Fig. 2) in the case of acetone sensing. The figure also reports the response of pure $\mathrm{WO}_{3}$, widely recognized as a powerful acetone sensor. So the comparison clearly shows that "painting" the surface of $\mathrm{TiO}_{2}$ with the $\mathrm{WO}_{\mathrm{x}}$ layer can boost its response by more than three orders of magnitude [3], up to the performance of pure $\mathrm{WO}_{3}$.

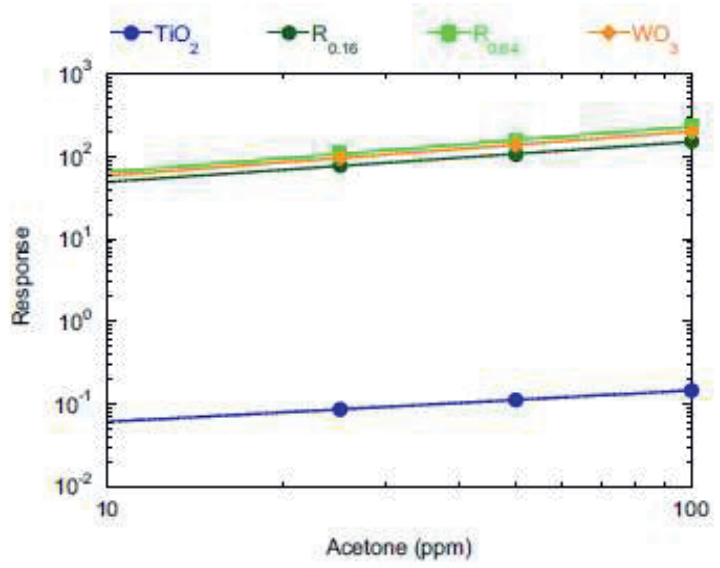

Fig. 2. Calibration curve for acetone at an operating temperature of $250{ }^{\circ} \mathrm{C}$ for the indicated sensors. The $R$ values indicate the $W$ atomic concentration with respect to Ti. (Modified with permission from [3]).

Finally, in the case of $\mathrm{TiO}_{2}-\mathrm{MoO}_{3}$ [4] (Fig. 3) analogous considerations can be drawn, enhanced by the fact that $\mathrm{MoO}_{3}$ alone is not known as a powerful acetone sensor. The obtained results demonstrated that indeed a suitable coupling of an oxide with a more catalytically active oxide onto the surface of the first can be a powerful tool for enhancing the sensor response. Hence, a plethora of other systems can be built, based on catalysis literature or insightful design of the electronic structure of the final composite material. Open issues concern mainly the determination of the sensing and charge transport mechanism and selectivity properties, related to the selectivity pattern of the uppermost oxide layer.

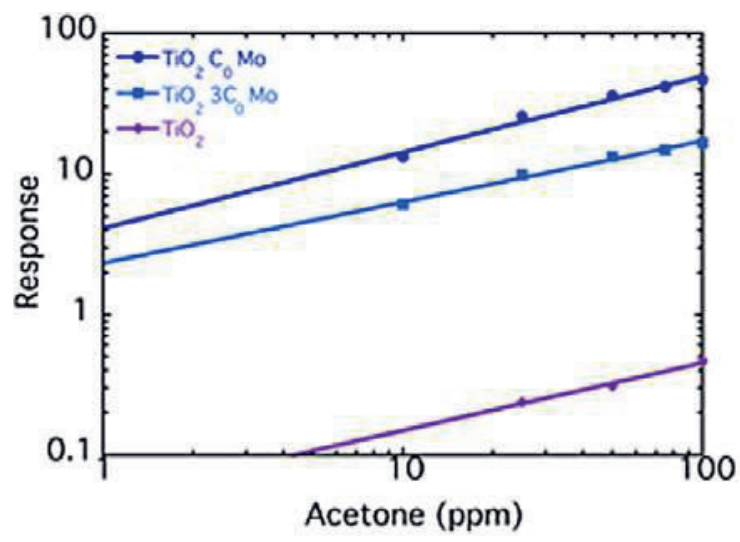

Fig. 3. Calibration curves for acetone at $300{ }^{\circ} \mathrm{C}$ for the indicated devices. $C_{0}$ is the $23 \%$ nominal atomic Mo concentration with respect to Ti. (Modified with permission from [4]).

\section{References}

[1] M. Epifani, R. Diaz, C. Force, E. Comini, T. Andreu, R. R. Zamani, J. Arbiol, P. Siciliano, G. Faglia, J.R. Morante, Colloidal Counterpart of the $\mathrm{TiO}_{2}$-Supported $\mathrm{V}_{2} \mathrm{O}_{5}$ System: A Case Study of Oxide-on-Oxide Deposition by Wet Chemical Techniques. Synthesis, Vanadium Speciation, and Gas-Sensing Enhancement, J. Phys. Chem. C 117, 20697-20705 (2013); doi: 10.1021/jp406518w

[2] M. Epifani, R. Diaz, C. Force, E. Comini, M. Manzanares, T. Andreu, A. Genç, J. Arbiol, P. Siciliano, G. Faglia, J. R. Morante, Solvothermal, Surface Modification of $\mathrm{TiO}_{2}$ Nanocrystals by $\mathrm{WO}_{\mathrm{x}}$ Coating or Wrapping: Solvothermal Synthesis and Enhanced Surface Chemistry, ACS Appl. Mater. Interfaces 7, 6898-6908 (2015); doi: 10.1021/acsami.5b00632

[3] M. Epifani, E. Comini, R. Díaz, A. Genç, T. Andreu, P. Siciliano, J. R. Morante, Acetone Sensors Based on $\mathrm{TiO}_{2}$ Nanocrystals Modified with Tungsten Oxide Species, J. Alloys Compd. 665, 345-351 (2016); doi: 10.1016/j.jallcom.2016.01.077

[4] M. Epifani, S. Kaciulis, A. Mezzi, D. Altamura, C Giannini, P.-Y. Tang, J. R. Morante, J. Arbiol, P. Siciliano, E. Comini, I. Concina, Solvothermal Synthesis, Gas-Sensing Properties and Solar Cell-Aided Investigation of $\mathrm{TiO}_{2}-\mathrm{MoO}_{x}$ nanocrystals, ChemNanoMat 3, 798-807 (2017); doi: 10.1002/cnma.201700160 